Teaching \& Learning (2011) 6(1), 83-94

\title{
The views of teachers toward the Balanced Day schedule in five elementary pilot schools in southern Ontario
}

\author{
LORI PEEBLES \\ Vice Principal, Waterloo Region District School Board \\ DR. KRISTIAN JOHN KIRKWOOD \\ Nipissing University
}

\begin{abstract}
Using a case study method to describe the experience of the teachers of five Ontario elementary schools to implement the Balanced Day schedule in the 20042005 school year, data sources included questionnaires completed by teachers from the pilot schools, which were administered at the beginning of the year and at the end of the year, and three focus group interviews from one school, conducted twice during the year. Findings indicate that, overall, teachers perceived the Balanced Day to be more effective than the traditional schedule for student learning, and that the schedule also resulted in changes to their own instructional practices that positively impacted student learning.
\end{abstract}

\section{Introduction}

Elementary schools are constantly changing and evolving in the areas of curriculum, teaching practices and assessment methods. One area that has not seen much change is the general school day schedule. For years, many elementary schools have had a traditional schedule of a short morning and afternoon recess, and a long lunch hour, and for the most part, this schedule has stayed the same. During the 2000-2001 school year, Michael Walmsley and his staff at a school in Ontario, introduced a "Balanced Day” (BD) schedule. A balanced day schedules three 100-minute blocks for instruction and two 45-minute breaks. The break times allowed students to eat inside and have time to play outdoors. After being on the BD schedule for a year, other schools in the board incorporated the BD, and the idea started to spread to other schools and boards in Ontario (Personal Communication, August 30, 2005).

Research has indicated that the Balanced Day was developed due to several issues caused by the traditional scheduling of classes. First of all, the Balanced Day schedules instruction in three blocks of time. Williams (1999) found that a longer block of time was better for the delivery of instruction because "ninety-minute classes allow a teacher to develop an entire idea 
in one setting rather than to extend it in several consecutive installments” (p. 16). The BD allows students the necessary time to learn the material, make higher level connections, or for the struggling students, be able to grasp the basic concepts. (Huff, 1995, as cited in Williams, 1999) stated that:

Instructors will have additional time to develop key concepts fully and to ask probing questions. This should allow students to master the material and not be confused about the lesson and concepts being taught. The extra time offered in block classes is often critical for struggling students and allows advanced students to explore advanced materials in which they are interested. (p. 25)

The BD allows teachers the opportunity to teach using manipulatives and a variety of hands-on activities and teaching styles that require larger blocks of time to implement, and research shows that these practices address every student's learning needs. "[Teaching in the longer blocks of the Balance Day] requires different instructional approaches and allows teachers to use various strategies in a single period” (Bryant \& Bryant, 2000, p. 9). Irmsher (1996) commented that "larger blocks of time allow for a more flexible and productive classroom environment, along with more opportunities for using varied and interactive teaching methods” (p. 3).

Fewer transitions in the day also means that students have more time on task in the classroom. Fox, Hoskin, Short, and Woehrle (2003) found that it takes between six and seven minutes for students to be ready for instruction after the recess bell rings. Add to this figure the approximately five minute estimate that it takes for students to get ready before recess, and, in the traditional school day, most children will use 33 minutes per day in transitions. With only two breaks, that number will decrease to approximately 22 minutes per day. In one week alone, students will have 50 minutes more instructional time with the BD than the traditional day. Reducing transitions results in increased learning time, improved classroom management, and ultimately more learning for students (Winn, Menlove, \& Zsiray, 1997). Williams (1999) explained that fewer transitions also help teachers, because with fewer classes to teach in a day, there is less time with class openings and closings, resulting in fewer transitions and increased instructional time.

The research on nutrition and learning indicates that children need smaller meals more frequently, in order to stay alert and focused in class. Jensen (1995) stated, "Make sure your 
learners are given several opportunities to eat nutritious snacks throughout the day” (p. 158). “Research has proven that well-fed bodies help young brains work better” (Kalinowski, 2003, p. K4). "In another study in Mexico, Cravioto reported that well-fed learners rated higher in communication skills and did better in the classroom” (Jensen, 1996, p. 74). The BD provides this scenario, and the teachers in the focus group could definitely see the benefits of students eating later in the day. Although the students had three breaks with the traditional school day, the two recess breaks were more a playtime than a structured eating time.

According to the research, meaningful exercise is also an important component of a healthy learning environment. The BD allows students to eat inside rather than try to have a snack while playing or exercising. It is difficult for students to run around and exercise when they are trying to snack, and the BD provides opportunity for both necessary activities at separate times. "The mind, brain, and body are one. When children are deprived of vigorous recess activities the body's heart isn't given the opportunity to pump fresh oxygen into the blood to nourish a sluggish brain” (International Play Association, n.d.).

The research also recognizes the benefit of teachers having time to network and build learning communities with colleagues, which allow teachers to discuss planning and assessment strategies, which will inevitably improve student learning (Winn et al., 1997, p. 10). The BD allows students to have a balance of learning, nutrition, and exercise, and all of these components are crucial for a student to be a successful learner. In the 2004-2005 school year, five pilot schools, selected from a public school board in Ontario, joined a pilot project to implement the BD. The purpose of this research was to present the qualitative experience of the teachers in one of the pilot schools and their perspectives on the impact of the new schedule on their students.

\section{Methodology}

The research design uses a qualitative approach (Creswell, 2005) to describe the experiences of the teachers in the five schools selected for the pilot study. Data sources included questionnaires completed by teachers, students, and parents from the pilot school, at the beginning of the school year. Respondents answered questions based on the traditional school day that teachers, students and parents had always experienced at that school. These questionnaires were completed in the fall of 2004. A second questionnaire was completed in the 
spring of 2005, and included the same questions as the first questionnaire, but they were based on the BD which schools had piloted that entire school year. The questionnaires for the teachers had a four-point scale. The descriptors were: Always, Sometimes, Rarely, and Never. Questionnaires were analyzed for descriptive statistics.

Additional data sources included focus group interviews from teachers, students, and parents from the pilot school. The focus groups were conducted twice during the pilot project. At both sessions, the groups discussed the same questions. The transcripts from the focus groups were coded by two researchers independently to determine patterns, which were then categorized and grouped in themes (Creswell, 2005).

\section{Findings}

\section{Questionnaires}

For the teacher questionnaires, there were substantial differences between the initial questionnaire focused on traditional schedules and the questionnaire focused on BD. For discussion purposes, percentages will be used with the focus being on the Always descriptor (see Table 1). The most significant difference was shown in the question, Students were focused in the afternoon. The traditional schedule questionnaire showed that $2 \%$ of the teachers said Always, while $47 \%$ said Always in the BD questionnaire. This suggests that students are better able to focus in the afternoon with the BD. 
The views of students, parents, and teachers

Table 1

Percentages - Teachers

\begin{tabular}{|c|c|c|c|c|c|c|c|c|}
\hline \multirow[t]{2}{*}{ Statement } & \multicolumn{4}{|c|}{ Pretest percentages (Fall) } & \multicolumn{4}{|c|}{ Posttest percentages (Spring) } \\
\hline & A \% & $\mathrm{S} \%$ & $\mathrm{R} \%$ & $\mathrm{~N} \%$ & A \% & $\mathrm{S} \%$ & $\mathrm{R} \%$ & $\mathrm{~N} \%$ \\
\hline $\begin{array}{l}\text { Students had enough } \\
\text { time to complete their } \\
\text { work in class }\end{array}$ & 10 & 86 & 3 & & 49 & 51 & & \\
\hline $\begin{array}{l}\text { Students were rushed in } \\
\text { class }\end{array}$ & 5 & 80 & 14 & 2 & 2 & 14 & 67 & 16 \\
\hline $\begin{array}{l}\text { You had time to work } \\
\text { with individual students } \\
\text { during class }\end{array}$ & 21 & 57 & 22 & & 35 & 61 & 5 & \\
\hline $\begin{array}{l}\text { You had enough time to } \\
\text { cover the curriculum }\end{array}$ & 11 & 54 & 19 & 16 & 49 & 47 & 5 & \\
\hline $\begin{array}{l}\text { You had time to } \\
\text { implement different } \\
\text { teaching strategies }\end{array}$ & 35 & 60 & 5 & & 72 & 28 & & \\
\hline $\begin{array}{l}\text { Students appeared } \\
\text { relaxed in class }\end{array}$ & 37 & 61 & 2 & & 68 & 33 & & \\
\hline You felt relaxed in class & 39 & 51 & 9 & 2 & 67 & 28 & 5 & \\
\hline $\begin{array}{l}\text { Students were focused in } \\
\text { the morning }\end{array}$ & 38 & 62 & & & 69 & 29 & 2 & \\
\hline $\begin{array}{l}\text { Students were focused in } \\
\text { the afternoon }\end{array}$ & 2 & 78 & 20 & & 47 & 51 & & 2 \\
\hline $\begin{array}{l}\text { Students brought } \\
\text { nutritious lunches }\end{array}$ & 2 & 85 & 13 & & 10 & 88 & 2 & \\
\hline $\begin{array}{l}\text { Students brought } \\
\text { nutritious snacks }\end{array}$ & & 59 & 41 & & 7 & 88 & 5 & \\
\hline $\begin{array}{l}\text { Students ate the majority } \\
\text { of their lunch }\end{array}$ & 20 & 75 & 6 & & 47 & 51 & 2 & \\
\hline $\begin{array}{l}\text { Students used outdoor } \\
\text { times for play and } \\
\text { exercise }\end{array}$ & 36 & 64 & & & 74 & 26 & & \\
\hline $\begin{array}{l}\text { Students used outdoor } \\
\text { times to eat their snacks }\end{array}$ & 28 & 60 & 10 & 2 & 5 & 9 & 19 & 67 \\
\hline $\begin{array}{l}\text { Students had sufficient } \\
\text { time to participate in } \\
\text { extra-curricular activities }\end{array}$ & 36 & 47 & 16 & 2 & 26 & 57 & 10 & 7 \\
\hline
\end{tabular}

Note. $\mathrm{A}=$ Always; $\mathrm{S}=$ Sometimes; $\mathrm{R}=$ Rarely; $\mathrm{N}=$ Never. 
The statement, Students had enough time to complete their work in class, showed $10 \%$ of the teachers saying Always on the traditional schedule questionnaire, and $49 \%$ of the teachers saying Always on the BD questionnaire. This is a significant increase of 39\%, which suggests that teachers perceived that the BD gave students more time to complete work. The statement, Students used outdoor time for play and exercise, showed teachers saying Always 36\% of the time on the traditional schedule questionnaire, and 74\% of the time for the BD schedule questionnaire. This is a significant increase, which shows that teachers perceived that the BD allowed students to use their outdoor playtime for exercise.

The questionnaires indicated that teachers also perceived an improvement in the following areas: covering (or teaching) the curriculum, time to implement different teaching strategies, students appearing more relaxed in class, and improved student focus in the morning. The teachers' questionnaire answers gave a definite, strong message that they perceived the BD to be beneficial to their students.

\section{Focus Group}

Four themes emerged from the analysis of the transcripts from the focus group: instructional time, student focus, nutrition, and outdoor playtime,

Instructional time. At the first meeting in November, teachers felt that 50-minute periods were ideal for some subjects, but too long for others. Sometimes they were left with small bits of time (15 or 20 minutes), and it was difficult to always use that time effectively. For example, two teachers commented:

I'm finding with some of the things 100 minutes is too long. I do like the big blocks of time for the language, for the math, they are optimum. (Teacher 1)

Speaking from a support teacher position, I do find the instructional time more optimal.

I'm finding that just the two, for a lack of a better word, interruptions are good for maximizing the instructional time that I have because there [are] only the two times that I have to think about getting them back to get ready. Whereas before it was recess, then lunch, and then.... I am finding there is more optimal time for a support position. (Teacher 3) 
At the February focus group meeting, teachers were asked the same questions and seemed more positive about the longer blocks of time. Implementing the BD for five months had allowed teachers to make a shift in their teaching practices, and be able to use the longer blocks of time to the students' advantage. Time for consolidation, flexibility, effective teaching strategies, crosscurricular connections and being able to go deeper into curriculum, were all benefits of the BD. Comments from teachers included the following:

I think especially for subjects such as math, when you really do need that time for the kids to consolidate whatever it is they are being taught. To have the 100 minutes is incredible. You don’t have to spill off into another period after a recess or a nutrition break as you usually do with the regular day. (Teacher 5)

It just gives you that flexibility too, that even if you've planned a 50-minute lesson and it runs longer, as you were saying, and it runs 70 minutes, it all works out. It just makes sense for the flexibility. (Teacher 1)

I was able to plan effectively as a teacher and use different strategies like a three-part lesson; then the students were really getting a lot more out of it and I found that they were really able to understand the material a whole lot more than they would have in a 37.5minute period. (Teacher 5)

I like too how there [are] 6 periods as opposed to 8. Like 8 was so disjointed, but like I even find with the kids you can even go with, like what you would normally do with a science lesson, you would be more surface, but with those extra minutes you can actually go deeper and go into it with much more depth, which is what I like about it. (Teacher 7)

Student focus. In the first meeting, all of the teachers agreed that both primary and junior students were able to focus better throughout the entire day, especially in the afternoon.

I find that I don't feel that there are ups and downs throughout the day. I feel that almost anything that I can do in the morning or the middle or the end of the day, I can reorganize it and still get a similar quality. (Teacher 2)

You don’t have the after-recess 2:30-3:30 downtime where you couldn't bring in anything new. Language can be done at the end of the day, math can be at the end of the day, anything can be at the end because they are all there, they are up, they are all ready. (Teacher 4) 
Even teaching grade one I still find that too. I didn't think I would get anything done teaching language in the afternoon, but for the first while they were still worried about playtime, but after a month, they could work right until 3:20, and that surprised me. (Teacher 8)

At the February meeting, teachers were still in agreement that students are more focused on the BD schedule. They continued to have positive responses when asked if students are more focused in class, including:

Absolutely, especially that last 100 minutes. It used to be a write-off especially with the little kids. (Teacher 1 )

And nobody ever asks anymore, “Is it over yet? Is it done yet? Are we finished?” Like that time flies because it’s active learning. (Teacher 1)

Nutrition. At the meeting in November, teachers were asked if their students were eating healthier foods, and if they were eating most of their lunches. Teachers agreed that students were eating healthier foods, but that there was still room for improvement. Teachers commented: I also found that junk food is coming, but the good stuff is still there, more of the good stuff is there. There is more fruit because they are eating twice, the fruit's there, the bagels are there, the fruit juices, the milk, there [are] also a few chips and chocolate bars and things like that, but they are less. It's not their whole lunch. (Teacher 4) From what I've seen from doing lunch duty, I do think overall that the foods seem healthier; there is still quite a bit of junk food out there, and as we said, it is pretty spread out, but we still have some work to do with the parent community. Overall I think it's improved, but there are things that we need to do to help it improve a little more. (Teacher 3)

At the February meeting, teachers reported that there had been a decrease in healthy foods. Teachers still agreed that the two nutrition breaks increased the chances of students eating healthy foods at some point in the day, but they felt that students and parents needed to continue to be educated about healthy choices, and explained it this way:

There has been a decrease, because it was such a push at the beginning of the year. It used to be more focused on veggies and dip and stuff like that, but now it is pastries and chips. (Teacher 8) 
Those that are eating at both nutrition breaks are eating healthy. I probably have about 5 or 6 students in my class that I am concerned about. (Teacher 4) I find it a bit different. I find the kids in my room are actually eating healthy, all things considered. They will split their sandwich and have half of the sandwich in the morning and half of the sandwich at 1:00, and I mean, sure there's some junk, but they are eating something that's healthy. (Teacher 7)

I guess we could still probably concur that even though they aren't always eating healthy food, those bodies are hopefully getting food twice... I know it's junk, it's still the blood sugar thing, but maybe that aside, the breaks are still at the right times for the kids. (Teacher 10)

Outdoor playtime. At the November focus group meeting, teachers were asked how students were using their outdoor playtime. Teachers agreed that students were using the outdoor playtime for meaningful exercise, and that 20 minutes was enough time to get into a game, but not enough time for major problems to arise. Three of the teachers' comments included:

I was just amazed with that number of children, I watched them, and they were all playing like I’ve never seen kids play before. We were pretty good last year, but there was always that group of kids that would just stand around and not really know what to do with themselves. I purposely looked around [this year] and there were kids in the field playing soccer and kids on the tarmac with ball games that were really playing it in the way it was intended to play, and another group with their hockey sticks, another group skipping, they were truly playing, which was just so heartwarming. (Teacher 3) My class seems happier on the whole, whereas [last year] I can remember little silly things when they would come in like so-and-so taking their ball or taking their space or whatever, but on the whole [this year] they come in refreshed and happy and there [are] not a lot of complaints. (Teacher 1 )

The other thing that we haven't mentioned is it is 20 minutes of playtime and they don't have the extra 10 minutes to maybe have the game fall down or break down or relationships break down. (Teacher 3)

Teachers didn't have much new information to share at the February meeting, but they agreed that the outdoor time was still being used for good quality exercise. 
The views of students, parents, and teachers

They are running around; they come in red-cheeked. (Teacher 4)

Even the grade 6s are running around. I'm surprised. In a good way. (Teacher 7)

The focus groups and questionnaire results confirm that the teachers felt that the BD schedule impacts students in a very positive way.

\section{Challenges}

Change can always bring some challenges, and the BD schedule was no exception. At the November focus group meeting, teachers said that it was difficult to shift their teaching practices to include the longer blocks of time. Teachers stated their concerns:

If I had one complaint, my time is not used as well and I don't feel that my days are organized as well, and I'm not sure how to change that. Language is fitting in well, but it's about the only thing that I am fitting in well. (Teacher 2) It's an organizational thing. I'm switching to science and it is a 50-minute block, but I don't have everything here, so recess last year I would have gotten everything out and all of the equipment, so sometimes it's just, for me, stressful. But for the kids it's fine, but for me as a teacher, it's how do I organize myself throughout the day so that I'm well prepared so that I don't have to make those stops at breaks. (Teacher 4)

Longer blocks of time meant that teachers had longer planning times, but less often. One teacher explained the challenge:

The planning time was difficult to get used to as well. Just having the 3 days of planning and on those 2 days [when you did not have it], if you were lucky not to have supervision, it was easy to survive. But I know some people have supervision on the days that they don't have planning time, and they feel more scrambly. (Teacher 1)

Another area that proved challenging was coordinating the BD schedule with other scheduling in the board, and with the kindergarten classes in the schools. Kindergarten teachers were on a very different schedule, so they never had breaks at the same time as the rest of the school. Additionally, some of the teachers dealt with problems regarding the recruitment of supply teachers, and conducting/participating in half-day workshops was discussed. The teachers felt that this problem would happen less often if the entire board were on the BD schedule. Even taking students on field trips required more planning and set up time. The field trip locations were still running their programs on the traditional day with a lunch hour, so there were some 
challenges to booking trips. However, overall, the teachers felt confident that they had dealt with the challenges of the new schedule effectively.

Teachers were very positive about the BD at the November meeting, and felt that it was best for students, even if it was not always best for teachers.

I want to echo what was said earlier. It seems to be very positive for kids. I don't think there is any doubt that this has maximized their learning. But it is more challenging than I thought for me. I was really gung ho, I was really excited. Sometimes the days go too quickly. If you're not really organized by quarter to nine, you are in trouble all day long, really keeping your head above the water, so that is a challenge. (Teacher 9)

But I would never.... for what the children are able to do, it’s wonderful. I wouldn't give that up for anything - ever. (Teacher 2)

At the February meeting teachers were asked if they would want to go back to the traditional schedule, and they all said no. Teachers talked about the BD schedule being great for students, and were willing to put the students' needs before their own.

But it goes back to what is best for kids, and if that is your philosophy, you have to put aside what is best for me. Yeah. We have to make sure we can survive the day, but in a way I sometimes wonder if it is that big of a deal, or a thing to get all worked up about. It's just a schedule. (Teacher 10)

The teacher focus group was able to share a wealth of information about the BD schedule. Unlike the parents, they actually experienced it on a daily basis, and unlike the students, they were better able to articulate the ways that it affects students. There were challenges that continued throughout the year, but these teachers were willing to put the students first, and work to overcome the difficulties.

\section{Discussion}

In this case study, the BD schedule provided a learning environment where students were able to focus, have time to learn, eat healthy food, and have adequate time for exercise and extracurricular activities. As implemented in this pilot school, the Balanced Day schedule supported how students learned. The teachers in these schools felt that their students were given additional time in which to learn at their own pace, with less time being spent on transitions. As well, teachers felt that student focus was improved with the longer breaks for nutrition and 
exercise. Although the teachers felt that, over the year, parents needed more information about the types of nutritional snacks they should be sending with their children to school, overall, they had positive feelings about the use of nutritious breaks to enhance the learning experience for students. Teachers stated that they were able to definitely see the benefits of students eating later in the day.

For many people, the idea of change can be frightening and unappealing, and implementing the BD was no exception. Many teachers, students, and parents were apprehensive when the BD pilot project began. There were many unanswered questions as to how all of the major stakeholders would cope. Initially there were some speed bumps that had to be overcome, but the community of the school used innovative thinking, creative collaborative problem solving, and time to sort through the experience.

The BD schedule will not solve every problem in education, but it will give students an opportunity to experience learning in a balanced setting that will help them to reach their full academic potential. It is axiomatic that no one study provides a panacea; nevertheless, it is only through the accumulation of specific facts that contributions to knowledge can be made. As such, this study makes a contribution to the debate on the balanced school day.

\section{References}

Bryant, C., \& Bryant, R. (2000). Social studies in the block schedule: A model for effective lesson design. Social Studies, 91, 9-16.

Creswell, J.W. (2005). Educational research: Planning, conducting, and evaluating quantitative and qualitative research. Upper Saddle River, NJ: Pearson Merrill Prentice Hall.

Fox, S., Hoskin, B., Short, K., \& Woehrle, T. (2003). Thinking outside the clock: Reorganizing the school day. OPC Register, 5(4), 12-17.

International Play Association. (n.d.). The case for elementary school recess. Retrieved from http://www.ipausa.org/recesshandbook.htm

Irmsher, K. (1996). Block scheduling. ERIC Digest, 104, 1-6.

Jensen, E. (1995). The learning brain. San Diego, CA: Turning Point.

Jensen, E. (1996). Brain-based learning. Del Mar, CA: Turning Point.

Kalinowski, T. (2003, August 30). Balance is better. Toronto Star, pp. K1, K4.

Lewis, R. W. (1999). Block scheduling: Changing the system. (Unpublished manuscript). University of West Alabama.

Williams, L. M. (1999). Effects of block scheduling on grade point averages. (Unpublished master's thesis). Salem-Teikyo University, Salem, WV.

Winn, D. D., Menlove, R. R., \& Zsiray, S. (1997). Rethinking the scheduling of school time. Bloomington, IN: Phi Delta Kappa Educational Foundation. 